\title{
Effects of advanced maternal age on pregnancy outcome
}

\author{
Neelam Rajput ${ }^{1}$, Deepak Paldiya ${ }^{1 *}$, Yogendra S. Verma ${ }^{2}$ \\ ${ }^{1}$ Department of Obstetrics and Gynecology, ${ }^{2}$ Department of Pediatrics, Gajra Raja Medical College, Gwalior, India
}

Received: 28 August 2018

Accepted: 10 September 2018

\author{
*Correspondence: \\ Dr. Deepak Paldiya, \\ E-mail: neelamkrhgwl@rediffmail.com
}

Copyright: $\odot$ the author(s), publisher and licensee Medip Academy. This is an open-access article distributed under the terms of the Creative Commons Attribution Non-Commercial License, which permits unrestricted non-commercial use, distribution, and reproduction in any medium, provided the original work is properly cited.

\begin{abstract}
Background: Advanced maternal age, generally signify age after 35 years at the time of delivery. It is associated with decreased fertility and increased risk.

Methods: This was a prospective study conducted in Kamla Raja Hospital, G.R. Medical College, Gwalior (M.P.) during the period of one year from July 2015 to June 2016. Pregnant women aged 35 years and older at the time of delivery were selected and analyzed for maternal and perinatal outcome.

Results: A total no. of 288 elderly pregnant patients were selected for the study. Most of the cases were in the age group 35 to 39 years $(89.93 \%)$. Multi gravida $(71.8 \%)$ and grand multi para $(22.22 \%)$ constituted the largest group. Most of the cases belong to lower socio-economic status (90\%). Percentage of unbooked cases was $82.98 \%$. The causes of delay in pregnancy were preference for male child $(23.95 \%)$ and unwareness of contraception $(21.52 \%)$. The incidence of diabetes mellitus and chronic hypertension were increased. Overall cesarean rate was increased (35\%). Incidence of abortions $28(9.72 \%)$, preterm delivery $18(6.25 \%)$, oligohydramnios $18(6.25 \%)$, APH 18(6.25\%) and PROM 17(5.90\%), low birth weight baby 30(13.19\%), NICU admission 20 (6.94\%), IUGR 11(3.81\%) all were high. The preference for male child $69(23.95 \%)$ and lack of awareness $62(21.52 \%)$ were two major reason for continuing pregnancies and deliveries till late age.

Conclusions: The present study showed that pregnancy at advanced age is a higher risk pregnancy in term of increased maternal and perinatal morbidity and mortality.
\end{abstract}

Keywords: Advanced maternal age, Elderly gravida, Maternal and perinatal outcome, Preterm deliveries

\section{INTRODUCTION}

Advanced maternal age generally held to signify age after 35 years at the time of delivery. It is the term that implies decreased fertility and increased risk. ${ }^{1}$ A significant proportion of women are electing to postpone their pregnancy well late into the fourth and fifth decades. ${ }^{2}$ the trend of delaying the pregnancy and child bearing is rising globally irrespective of race and economic status.

The wide educational and career choices encourage women to pursue their professional goals. Easy access to modern contraceptive methods has enabled them to achieve better control of fertility. 3 Increasing rates of divorce is another cause for delay in conceiving. Primary and secondary infertility due to various reasons may also cause a delayed conception. In India, the scenario is different where poor socio-economic status, lack of contraceptive knowledge, religious issues, desire for male child, concept of large family and women conceiving from marriage to menopause, are the common causes of pregnancy with advanced maternal age. The older women to conceive spontaneously was 57 years of age and with ART, the oldest was 66 years of age, recorded in literature. ${ }^{3}$

Pregnancy after the age of 35 years can be a challenge because of the maternal and foetal risk. The chronic 
hypertension, diabetes mellitus, subfertility, miscarriage, ectopic pregnancy, anemia, antepartum hemorrhage, malpresentation, postpartum hemorrhage lead to increased incidence of instrumental deliveries and cesarean sections. Foetal and neonatal risk is also high due to increased incidence of chromosomal abnormalities (mainly Down's syndrome), multiple pregnancy, IUGR, prematurity leading to higher number of NICU admission. Perinatal morbidity and mortality in increased in these patients.

\section{METHODS}

It was a prospective study conducted in the Department of Obstetrics and Gynaecology, Kamla Raja Hospital, G.R. Medical College, Gwalior (M.P.) during the study period of one year from July 2015 to June 2016.

A total of 288 admitted consecutively Pregnant women above the age 35 years and older were selected. Exclusion criteria were all pregnant woman admission below the age of 35 years, patients coming for medical termination of pregnancy even if they were more than thirty-five years of the age, patients not willing for participation in the study, patients with Chronic renal failure, severe cardiac disease, chronic liver disease, chronic lung disease like pulmonary tuberculosis and COPD etc.

All patients were analyzed for maternal outcome as abortion, ectopic pregnancy, preterm labour, PROM, Pregnancy induced hypertension, diabetes mellitus, antepartum hemorrhage, multiple pregnancies, perinatal outcome as uneventful outcome, preterm babies, NICU admissions, IUGR and mode of delivery. Information related to patient's demographical information, antenatal booking status, associated medical disorder, cause for delayed pregnancy, Complication during pregnancy, Mode of delivery, maternal and neonatal outcome was collected in a predesigned proforma.

\section{RESULTS}

It was observed that Majority $89.93 \%$ patient were from age group of 35 year to 39 years. Only 6 patients $(2.08 \%)$ were found above the age of 45 cases are from at and above 45 year.

Table 1: Cause of delay in pregnancy.

\begin{tabular}{|lll|}
\hline Causes & No. & Percentage \\
\hline Infertility & 19 & 6.59 \\
\hline Late Marriage & 7 & 2.43 \\
\hline Preference for male child & 69 & 23.95 \\
\hline Unawareness & 62 & 21.52 \\
\hline Un Know Cause & 131 & 45.48 \\
\hline
\end{tabular}

Analysis of parity status shows that $71.87 \%$ patient were Multi gravida and $22.22 \%$ are Grand multi gravid only $5.9 \%$ patient were primigravida. Maximum patient
(92.91\%) belong to lower Socio-economic status. Only $1.7 \%$ patient were from upper socio-economic class, $5.0 \%$ cases belong to upper middle and $55.55 \%$ belong to llower middle class. Education status analysis shows that $30.55 \%$ patient were uneducated, $19.79 \%$ were educated up to primary, $46.52 \%$ were educated up to Middle, $3.81 \%$ were educated up to High school. $01.44 \%$ were educated up to Higher secondary. Almost two third of the patients $(65.97 \%)$ were from urban areas and $34.03 \%$ were from rural areas. Majority of the cases were unbooked (82.98) only $17.02 \%$ cases were booked for antenatal care. It was observed that $3.74 \%$ patients had chronic hypertension and $2.08 \%$ patients had diabetes mellitus. Other medical disorders included Cardiac Disease $0.34 \%$, Hepatitis B $0.34 \%$, Hypothyroidism $0.34 \%$, Fibroid $0.34 \%$, Epilepsy $0.69 \%$. Observation of Causes of Delay in pregnancy reveals that preference for male child (23.95\%) and lack of awareness (21.52\%) were two major reasons for delaying pregnancy and delivery till late age (Table 1).

Table 2: Pregnancy outcome.

\begin{tabular}{|lll|}
\hline Outcome & No. & Percentage \\
\hline Vaginal delivery & 153 & 53.12 \\
\hline LSCS & 102 & 35.41 \\
\hline Abortion & 29 & 10.06 \\
\hline Laparotomy & 4 & 1.38 \\
\hline
\end{tabular}

Analysis of pregnancy outcome reveals that half (53.2\%) of the patients delivered vaginally, $35.41 \%$ underwent LSCS, $10.06 \%$ underwent suction and Evacuation for abortion, Laparotomy were performed in $1.38 \%$ for ectopic pregnancy (Table 2).

Table 3: Pregnancy complications.

\begin{tabular}{|lll|}
\hline Outcome & No. & Percentage \\
\hline Uneventful outcome & 155 & 53.81 \\
\hline Abortion & 28 & 10.06 \\
\hline Ectopic pregnancy & 4 & 1.38 \\
\hline H. mole & 1 & 0.36 \\
\hline Anemia & 14 & 4.86 \\
\hline PIH including eclampsia & 16 & 5.55 \\
\hline Preterm delivery & 18 & 6.25 \\
\hline Oligohydraminos & 18 & 6.25 \\
\hline Malpresentation & 13 & 4.16 \\
\hline Twin delivery & 3 & 1.04 \\
\hline PROM & 17 & 5.90 \\
\hline APH & 18 & 6.25 \\
\hline PPH & 26 & 9 \\
\hline
\end{tabular}

In the present study it was observed that $53.81 \%$ patient had uneventful outcome. Remaining patient had complication including abortion (9.72\%), Ectopic Pregnancy (1.38\%), Anemia (4.86\%), Pregnancy induced Hypertension $(2.77 \%)$, Eclamsia $(2.77 \%)$, Preterm Delivery (96.25\%), Oligohydramios (6.25\%), Malpresentation (4.16\%), Twin Delivery (1.04\%), 
Premature rupture of membrane $(5.90 \%)$, Antepartum haemorrhage $(6.25 \%)$ and Postpartum hemorrhage $(9 \%)$ (Table 3).

\section{Table 4: Perinatal outcome.}

\begin{tabular}{|lll|}
\hline Perinatal outcome & No. & Percentage \\
\hline Congenital anomaly & 6 & 2.08 \\
\hline Low Birth Weight & 38 & 13.19 \\
\hline Intrauterine foetal demise & 8 & 2.77 \\
\hline Neonatal ICU Admission & 20 & 6.94 \\
\hline Intra Uterine Growth Retardation & 11 & 3.81 \\
\hline Uneventful Outcome & 217 & 75.34 \\
\hline
\end{tabular}

Perinatal outcome was uneventful in $75.34 \%$ of patients. Congenital anomaly was seen in $2.8 \%$ of babies, $13.19 \%$ of neonates were Low Birth Weight baby, 6.94\% required NICU admissions, Intrauterine Death was seen in $2.77 \%$, and Intra Uterine Growth Retardation were $3.81 \%$ (Table 4).

\section{DISCUSSION}

The total no. of 8538 obstetric patients were admitted during the study period, out of them 288 were above the age of 35years at the time of admission. Incidence of pregnancy at advanced maternal age in this study is only $3.4 \%$ which is very less than that mentioned by Goldman J. et al in US (21\%) and Honque ME et al. ${ }^{4,5}$ But less than that reported by Giri et al, $(4.53 \%)$ and Priyadatt. D. Patel $2.95 \%$ which are comparable to present study it is because of difference in social preferences, economic differences, difference in the level of awareness, educational status, age at marriage, culture factors and difference in contraceptive practices. $^{6,7}$ Maximum number of patients were in the age group of 35-39 years $(89.93 \%)$, followed by $40-44$ years $(7.98 \%)$ and only $2 \%$ cases were found in the age group above 45 years. Study conducted by Rajmohan Laxmy et al revealed that $89.9 \%$ patients belonged to 35-40 years which is comparable to present study. Above data explains inverse relationship of age with fertility. The fertility is remarkably reduced with increasing age. Maximum number of cases are multigravida 202 cases $(71.87 \%)$ and grand multipara 64 $(22.22 \%)$ cases this is because of high fertility and large family size trends in India. Study conducted by Priyadatt. D. Patel mentioned the percentage of multigravida was 97.10. Which is comparable to present study (94.09\%). 64 cases were in the grandmultipara group explains that large family size trend is still continued in India, particularly among women of low socio-economic status and low education qualification. ${ }^{7}$ The smallest no. was among primi gravida. This is because of less number of late marriarge. In our country due Social and cultural reasons and lack of education and awareness. ${ }^{8}$ Women continue to produce children right from the beginning till the end of their reproductive career. Fertility decreases, and rate of miscarriage increases with advancing maternal age. ${ }^{19-21}$ Maximum number of cases were from lower middle and upper lower socio-economic class that is 160 cases $(55.55 \%)$ and 103 cases $(35.66 \%)$ respectively this is because of maximum population of both classes are attending the study hospital. Minimum no. of cases 5 $(1.7 \%)$ are from upper class, this is because of late marriages in this class. Minimum no. of cases $5(1.7 \%)$ are in lower class, because of early marriages in this class. This is because of lack of education, awareness and social preference of particular gender in lower middle Socio-economic status population. ${ }^{8}$ Also this Socioeconomic group contributed to the largest no. of population in India. Observation of literacy status reveal that maximum number of cases 134 (46.52\%) were educated up to middle class followed by uneducated cases $88(30.55 \%)$ and cases educated up to primary class $57(19.79 \%)$. This is because of level of literacy among Lower middle Socio-economic group is about $45 \%$, most of them do not continue their education after primary or middle classes. In present study incidence of diabetic mellitus was $2.08 \%$. Which is comparable to Study done by Giri et al. $1.1 \%$, Rehman et al, $1.96 \%$. Khalil et al. $2.4 \% .^{8,9}$ In present study incidence of chronic hypertension was $3.74 \%$ which is comparable to study done by Giri et al, 2.2\%, Benil et al, 5.2\% and Meenakashi et al, 2.2\%, As pregnancy progresses, maternal adaptation resulting in high flow, lower resistance circulation and decrease in mean blood pressure which is impaired in older woman leading to development of preeclampsia. ${ }^{10,11}$ The incidence of chronic hypertension higher with advancing age due to age induced atherosclerotic changes in maternal blood vessels. In present study major cause of advanced maternal age are desire for male child that is $23.9 \%$ and unawareness contraceptives $21.52 \%$. Infertility in present study infertility and late marriage counting $6.59 \%$ and $2.43 \%$.

Similar study conducted by Giri et al also shows desire for male child $21.1 \%$ as a cause for advanced maternal age which is similar to present study whereas causes like late marriage $13.3 \%$ and unawareness for contraception have $10 \%$ are not comparable to present study.

In present study caesarean section rate was $35.4 \%$. In studies conducted by Vidaver $\mathrm{J}$ et al, Usha IM et al, cesarean rate was $38.8 \%$, Khalil et al $29.7 \%$, Giri et al $30 \%$, Powde Anuya A 35\%. So results are comparable to present study. ${ }^{12,13}$

Studies consistently show that women above 35 year of age are more likely than younger women to be delivered by caesarean (Bayrampur and Heaman). ${ }^{14}$ There is almost linear increase in relationship between maternal age and uterine dysfunction in a continuous effect throughout the child bearing years as reported by Main et al, Greenberg et al, Treky et al. ${ }^{15-17}$

In present study abortion rate was found $9.7 \%$. In study conducted by Ramchandran $\mathrm{N}$ et al, rate was $9.5 \%$ which is comparable to present study. ${ }^{18}$ In previous studies reporting the association of the maternal age with 
abortion. Majority of foetal losses occurred in 1st trimester and these could be attributed to aneuploidies.

Incidence of Aneamia in present study was found $4.16 \%$ which is comparable to those reported by Meenakashi et al, $2.9 \%$, Ramchandran et al, Rehman et al, $7.92 \% .{ }^{18-20}$

In the present study incidence of pregnancy induced hypertension cases were found in $2.77 \%$ comparable to that reported by Khalil et al $2.3 \%$ Rehman et al 3.96\%, Benli et al, $2.0 \% .^{20,21}$ The incidence of Pregnancy induced hypertension is higher among the elderly patient in comparison to non-elderly pregnant patient. This is because of Microvascular endothelial dysfunction which is basic pathology of Preclamsia, which is further accelerated with advanced maternal age.

Present study show percentage of PPH $9 \%$. Incidence in study conducted by Anuya A et al, 7\%, Amarin et al, $9.6 \%$, were comparable to present study. The incidence of Post-partum hemorrhage is higher advance maternal age because atonicity as a result of multiparity and poor myometrial function. ${ }^{13,23}$

In present study incidence of ante partum hemorrhage was $6.25 \%$ which is comparable to study conducted by Giri et al (2012) 5.5\%. Anuya A et al, 5.2\%, In present study incidence of Malpresentation was $4.76 \%$ which is comparable to study conducted by Meenakashi et al, $5.9 \%$ Amarin et al, 6\%, Ramchandran $\mathrm{N}$ et al $4.76 \%$. Multigravida and advancing age favor malpresentation because of lax abdominal wall. ${ }^{23}$

This study shows incidence of Preterm delivery as high as $6.25 \%$. Study done by Benli et al, have $5.8 \%$, are comparable to present study. The incidence of preterm delivery increases because of iatrogenic cause associated with advanced maternal age are chronic hypertension and diabetes mellitus and Antepartum hemorrhage. Malpresentation, twin pregnancy are also cause of preterm delivery in advance maternal age.

Percentage incidence of Twin delivery was $1.04 \%$. Study done by Meenakashi et al, have $1.5 \%$, Giri et al have $1.1 \%$ Rehman et al $1.9 \%$ which are comparable to present study. Because of availability of In Vitro Fertilization incidence of multiple pregnancy increases.

Incidence of ectopic pregnancy was $1.46 \%$. Study done by Anuya A et al $8.9 \%$, which in not comparable to present study because above study was conducted in Maharashtra region where better education with higher social status compared to Madhya Pradesh contribute to free availability of sex, adaptation of various contraceptive practices, easy availability of drugs for medical abortion leading to higher incidence of pelvic inflammatory diseases, leading to tubal block which may be reason for higher incidence of Ectopic pregnancy. Present study show incidence of oligohydramnios was $6.25 \%$ which is comparable to study done by Nagarwal et al $6.64 \% .^{24}$ Grandmultipara, poor nutrition, diabetes mellitus, vascular diseases and chronic hypertension are prevalent with advance maternal age which is responsible for higher incidence of Oligohydramnios.

In present study incidence of PROM was $5.47 \%$ comparable to results of study done by Giri et al $5.5 \%$. Present study shows incidence of Congenital Anomaly $2.08 \%$ comparable to study done by Benil et al, $1.3 \%$, Meenakashi et al, $3.3 \%$ The incidence of Congenital Anomaly among non-elderly patients is $0.34 \% .^{21}$ Poor oocvte quality, folic acid deficiency and less frequent ovulation are responsible for Congenital Malformation.

Incidence of IUGR was $3.81 \%$ in current study which is comparable to study done by Khalil et al, $4.7 \%$. Advancing maternal age is associated with a decrease potential for foetal growth possibly reflecting biologic ageing of maternal tissue and systems or the cumulative effects of diseases Leeks et al. ${ }^{22}$

Present study shows incidence of Low Birth weight Baby $13.19 \%$. Study done by Anuya A et al, 26\% and Meenakashi et al, $23.9 \%$ which are not comparable present study. In present studies 20 (6.94\%) new born babies admitted to NICU which is lesser than studies conducted by Priyadatt D. Patel who reported $15.66 \%$ of NICU admission. .,11,13,20 $^{-1}$

\section{CONCLUSION}

Young women should be encouraged to balance the biological advantage of having a child at younger age against the social and economic advantages of obtaining an education and establishing a career. They should be educated about the risks of delayed child bearing, age related risk of fetal anueplodies, the increased risk of both early and late complications of pregnancy. If conception has not occurred after 6 months of actively attempting pregnancy the couple should be referred to a clinician who can initiate an infertility evaluation and help formulate a plan to optimize the establishment of pregnancy. Older Women should be offered prenatal screening and prenatal diagnosis, targeted anomaly scan and liberal use of ante partum testing to ensure safe motherhood and a healthy foetus. In view of the increased morbidity and mortality associated with pregnancy in advanced maternal age they should preferably by taken care in tertiary referral centers.

\section{Funding: No funding sources \\ Conflict of interest: None declared}

Ethical approval: The study was approved by the Institutional Ethics Committee

\section{REFERENCES}

1. Laxmy R, Beena G. Pregnancy outcome in women of advanced maternal age. Int $J$ Bioassays. 2013;2(9):1193-8. 
2. Bianco A, Stone J, Lynch L, Lapinski R, Berkwiutz G, Berkowitz RL. Pregnancy outcomes at age 40 and older. Obstet Gynecol. 1996;87(6):917-22.

3. Chloe Zera, Ruth C. Fretts. Pregnancy and advanced maternal age. Progr Obstet Gynecol. 2007;17:11324.

4. Cleary-Goldman J, Malone FD, Vidaver J, Ball RH, Nyberg DA, Comstock CH, et al. Impact of maternal age on obstetric outcome. Obstet Gynecol 2005;;105(5):983-90.

5. Hoque ME. Advanced maternal age and outcomes of pregnancy: A retrospective study from South Africa. Bio Med Res 2012;23(2):281-5.

6. A Giri,1 VR Srivastav,1 A Suwal1 and AS Tuladhar290Advanced maternal age and obstetric outcome Med Coll J. 2012;15(2): 87

7. Priyadatt D Patel, Shital T Mehta, Babu S. Patel Advanced maternal age; facts, factors and fetomaternal outcome. Int J Sci Res.2016;5(1):22778179.

8. Najah Abdul Rehman, Archana Vikram, Najma Palakki, Nada Chettian Kandy. Maternal and fetal outcome in advanced maternal age. $\mathrm{J}$ of Evolution of Med and Dent Sci. 2015;4(6):2278-4748.

9. Khalil A, Yngelaki A, Maiz N, Zinevich Y, Nicoladies KH. Maternal age and adverse pregnancy outcome: a cohort study. Ultrasound Obstet Gynecol 2013;42(6):634-43

10. Benil AR, Benli NC, Usta AT, Atakul T, Koroglu M. Effect of maternal age on pregnancy outcome and cesarean delivery rate. J Clin Med Res. Feb 2015;7(2):97-102.

11. Sahu TM, Agarwal A, Das V. Advanced maternal age and obstetric outcome. J Obstet Gynecol India 2007;57(4):320-3.

12. Seoud M, Nassar A, Usta I, Melhem Z, Kazma A, Khalil A. Impact of advanced maternal age on pregnancy outcome. Am J Perinatol. 2002;19(1):1-7.

13. Pawde AA, Kulkarni MP, Unni J. Pregnancy in women aged 35 years and above: A prospective observational study. J Obstet Gynecol India. 2015;65(2):93-6.

14. Bayrampour H, Heaman M. Advanced maternal age and the risk of caesarean birth: a systematic review. Birth. 2010; 37(3):219.
15. Main DM, Main EK, Moore DH 2nd. The relationship between maternal age and uterine dysfunction: a continuous effect throughout reproductive life. Am J Obstet Gynecol 2000; 182(6): 1312.

16. Greenberg MB, Cheng YW, Sullivan M, et al. Does length of labour vary by maternal age? Am j obstet gynecol 2007; 197(4):428.e1.

17. Treacy A, Robson M, O’Herlihy C. Dystocia increases with advancing maternal age. Am J Obstet Gynecol 2006;195(3):760-3

18. Ramachandran N, Sethuraman D, Nachimuthu V, Natrajan T. Obstetric and perinatal outcome of elderly mothers aged 35 years and above: a comparative study. Int $\mathbf{J}$ Res Med Sci. 2015;3(1):214-9.

19. National Center for Health Statistics. Birth rate for women aged 15-44.

20. Centers for Disease Control. Assisted Reproductive Technology (ART) Report2002 National Summary (Accessed 5/5/05).

21. Tietze C. Reproductive span and rate of reproduction among Hutterite women. Fertil Steril 1957;12(5): 8997

22. Leeks KS, Ferguson RM, Corpuz M et al. Maternal age and incidence of low birth weight at term: a population study. Am J Obstet Gynecol 1988;158(1):84-9.

23. Amarin VN, Akasheh HF. Advanced maternal age and pregnancy outcome. East Mediterr Health J. 2001;7(4-5):646-51.

24. Nagarwal K, Chandrakanta GK, Manohar RK. Pregnancy outcome comparison in elderly and nonelderly primigravida. Int Multispeciality Journal Health. 2015;1(1):24-30.

Cite this article as: Rajput N, Paldiya D, Verma YS. Effects of advanced maternal age on pregnancy outcome. Int J Reprod Contracept Obstet Gynecol 2018;7:3941-5. 